\title{
Sosialisasi Pengaruh Stunting Terhadap Pertumbuhan dan Perkembangan Anak Usia Dini
}

\author{
Rr. Deni widjayatri ${ }^{1}$, Yulianti Fitriani ${ }^{2}$, dan Budhi Tristyanto ${ }^{3}$ \\ 1,2,3 Program Studi Pendidikan Guru Pendidikan Anak Usia Dini, Universitas Pendidikan \\ Indonesia \\ e-mail corresponden: deniwidjayatri@upi.edu
}

\begin{abstract}
ABSTRAK. Praktik membuat menu bekal bergizi untuk Anak Usia Dini (AUD) dan memberikan pemahaman taktis kepada orangtua mengenai stunting dan dampak yang diakibatkannya menjadi fokus utama yang dibahas dalam tulisan ini. Stunting merupakan dampak gizi buruk yang menyebabkan tidak optimalnya pertumbuhan dan perkembangan anak. Tujuan pengabdian ini adalah pencegahan stuntung dapat dilakukan sejak bayi dalam kandungan dan ketika anak memasuki usia pra sekolah dengan cara memberikan asupan gizi yang seimbang. Melalui kegiatan Pengabdian kepada Masyarakat (PKM) yang dibiayai oleh Program Studi PGPAUD Universitas Pendidikan Indonesia (UPI) Kampus Serang (KS) hasil kegiatan berupa sosialisasi materi terkait stunting dengan metode learning by doing. Sementara penulisan artikel dikemas dengan metode deskriptif dengan gaya narasi berupa gambaran kegiatan yang dilakukan selama proses PKM berlangsung. Peserta sosialisasi merupakan orangtua (Ibu) dan peserta didik TK Labshool UPI KS yang bersedia dilibatkan dalam proses pengabdian secara tatap muka, terbatas dan memaksimalkan penerapan protokol kesehatan karena pengabdian ini dilaksanakan di masa pandemi covid-19. Ruang lingkup kegiatan meliputi sosialisasi pengetahuan teoretis bagi Ibu, pengukuran tinggi dan berat badan anak serta kolaborasi peserta (Ibu dan anak) dalam menyusun menu makanan dengan gizi lengkap dan seimbang. Salah satu target luaran yang dihasilkan dari PKM ini yaitu buku saku menu bekal murah sehat bergizi, maka dapat direkomendasikan kepada orang tua maupun guru agar dapat menggunakannya sebagai alternatif acuan dalam menyediakan bekal bergizi bagi anak.
\end{abstract}

Kata Kunci : Stunting, buku menu bergizi, tinggi dan berat badan.

ABSTRACT. The practice of creating a nutritious lunch menu for Early Childhood (AUD) and providing tactical understanding to parents about stunting and its effects is the main focus discussed in this paper. Stunting is the impact of malnutrition which causes the growth and development of children to be not optimal. Prevention can be done since the baby is in the womb and when the child enters pre-school age by providing a balanced nutritional intake. Through Community Service (PKM) activities funded by the PGPAUD Study Program, Universitas Pendidikan Indonesia (UPI) Serang Campus (KS) the results of the activity are socialization of material related to stunting using the learning by doing method. While writing articles is packaged using descriptive methods with a narrative style in the form of descriptions of activities carried out during the PKM process. Socialization participants are parents (mothers) and TK Labshool UPI KS students who are willing to be involved in the face-to-face, limited service process and maximize the application of health protocols because this service was carried out during the Covid-19 pandemic. The scope of activities includes dissemination of theoretical knowledge for mothers, measurement of children's height and weight 
and collaboration of participants (mothers and children) in preparing a complete and balanced diet. One of the output targets produced from this PKM is a pocket book of cheap, healthy, nutritious lunch, so it can be recommended to parents and teachers so that they can use it as an alternative reference in providing nutritious provisions for children.

Keyword : Stunting, nutritious menu books, height and weight.

\section{PENDAHULUAN}

Pertumbuhan dan perkembangan anak dipengaruhi oleh banyak faktor diantaranya kesehatan dan gizi. Kesehatan ini dimulai sejak dalam kandungan termasuk asupan makan bergizi yang dikonsumsi oleh ibu selama mengandung. Apabila gizi yang diasup oleh tubuh tidak mencukupi maka hal tersebut menyebabkan pertumbuhan dan perkembangan janin menjadi terhambat. Jika kondisi ini terus berlangsung hingga 2 tahun maka pertumbuhan dan perkembangan anak mengalami hambatan. Hambatan pada pertumbuhan anak terlihat apabila berat badan dan tinggi badan tidak sesuai dengan standar WHO. Picauly dan Toy menjelaskan bahwa indikator yang digunakan untuk mengidentifikasi balita stunting adalah berdasarkan indeks tinggi badan menurut umur (TB/U) menurut standar WHO child growth standart dengan kriteria stunting jika nilai z score TB/U <-2 Standard Deviasi (SD)[1].

Kemenkes menegaskan bahwa salah satu permasalahan gizi yang menjadi perhatian utama adalah tingginya kejadian anak balita yang mengalami pendek (stunting). Balita pendek atau stunting adalah suatu kondisi pada anak yang gagal tumbuh karena kekurangan zat gizi kronis sehingga menimbulkan anak menjadi lebih pendek untuk usianya. Kondisi ketidaksesuaian ini disebut dengan pengerdilan atau stunting[2]. Akram mengemukakan kekurangan gizi adalah tantangan kesehatan yang dihadapi oleh seluruh masyarakat. Kekurangan gizi pada anak dapat berakibat pengerdilan. Pengerdilan merupakan kegagalan pertumbuhan searah, baik secara fisik maupun kognitif, karena gizi buruk dan infeksi sebelum dan sesudah kelahiran[3].

Menurut Almatsier pola makan adalah suatu usaha dalam pengaturan jumlah dan jenis makanan dengan gambaran informasi meliputi mempertahankan kesehatan, status nutrisi, mencegah atau membantu kesembuhan penyakit serta Konsumsi zat gizi merupakan faktor yang berpengaruh langsung terhadap status gizi[4]. Menurut beberapa ahli keperawatan diantaranya Paplau H mengatakan bahwa kesehatan adalah proses yang berlangsung mengarah kepda kretifitas, konstruktif, dan produktif. Dengan demikian bahwa kesehatan adalah suatu hal yang tidak dapat dianggap sepele keberadaannya dalam membentuk sumber daya manusia yang unggul. Bidang kesehatan perlu mendapatkan perlakuan dan perhatian khusus guna menunjang kepentingan pembangunan karakter bangsa[5]. Sementara Kismul mengemukakan bahwa dalam rahim, dan tingkat keparahannya secara bertahap meningkat hingga mencapai puncaknya pada sekitar 2 tahun, periode waktu yang disebut 1000 Hari Pertama Kelahiran[6]. Kirk menjelaskan bahwa stunting masa kanak-kanak berhubungan dengan keterlambatan perkembangan motoric dan tingkat kecerdasan yang lebih rendah. Selain itu, juga dapat menyebabkan depresi fungsi imun, 
perubahan metabolik, penurunan perkembangan motorik, rendahnya nilai kognitif dan rendahnya nilai akademik. Anak yang terhambat umumnya lebih rentan terhadap infeksi, terutama diare dan penyakit pernapasan serta malaria. Infeksi juga bisa meningkatkan malnutrisi, menciptakan lingkaran setan yang mengarah pada kekurangan pertumbuhan[7].

Konsekuensi fungsional dari pengerdilan berlanjut di masa dewasa, termasuk penurunan kapasitas kerja pada wanita, peningkatan risiko kematian selama persalinan dan hasil kelahiran yang buruk. Kesehatan anak yang bertempat tinggal di perkotaan dan di pedesaan juga menjadi salah satu faktor penentu gizi. Sehingga diperlukan adanya rancangan kebijakan dan intervensi nutrisi yang seimbang bagi kebutuhan fundamental optimalisasi kualitas gizi anak-anak, baik di kota maupun di desa. Adanya program posyandu, wajib memberikan ASI ekslusif hingga memberikan makanan bergizi seimbang menjadi slogan pemerintah Indonesia dalam menekan angka stunting.

Indonesia saat ini menempati urutan teratas pada permasalahan gizi buruk sehingga berakibat pengerdilan pada anak. Sehingga diperlukan edukasi kepada masyarakat untuk mencegah dan mengurangi prosentase gizi buruk di Indonesia. Menurut Atmojo unsur gizi merupakan salah satu faktor penting dalam pembentukan SDM yang berkualitas yaitu manusia yang sehat, cerdas, dan produktif. Gangguan gizi pada awal kehidupan akan mempengaruhi kualitas kehidupan berikutnya. Gizi kurang pada balita tidak hanya menimbulkan gangguan pertumbuhan fisik, tetapi juga mempengaruhi kecerdasan dan produktivitas ketika dewasa[8]. Pola makan pada anak usia dini sangat berperan penting dalam proses pertumbuhan pada anak usia dini, karena dalam makanan banyak mengandung gizi. Membentuk perilaku sehat anak dimulai sejak usia dini. Hal ini dikarenakan usia dini merupakan masa Usia keemasan. Masa Golden Age merupakan masa dimana tahap perkembangan otak pada anak usia dini menempati posisi yang paling vital yakni mencapai $80 \%$ perkembangan otak. Kondisi sehat dapat dicapai dengan mengubah perilaku yang tidak sehat menjadi perilaku sehat dan menciptakan lingkungan yang sehat dan bersih[9]. Membiasakan pola hidup sehat pada anak pada masa pandemi covid-19 dapat dilakukan dengan cara mengingatkan anak untuk memakan-makanan yang bergizi seperti sayur dan buah, berolahraga teratur dan istirahat yang cukup serta berjemur setiap pagi sekitar 10-15 menit. Selain mengingatkan guru juga memberikan kegiatan sederhana kepada anak yang disampaikan melalui rekaman video atau rekaman suara kepada anak. Sedangkan untuk menerapkan pola hidup bersih berdasarkan hasil wawancara dengan guru lembaga PAUD dan orangtua siswa dapat disimpulkan bahwa guru memberikan kegiatan untuk membiasakan pola hidup bersih kepada anak seperti membiasakan anak melakukan cuci tangan dengan sabun, dan menjaga kebersihan diri sendiri. Pembiasaan pola hidup sehat dan bersih dapat terwujud apabila ada kerjasama antara guru dan orangtua[10]. Perilaku hidup bersih dan sehat anak usia dini di lingkungan keluarga sudah berjalan sangat baik di tengah pademi covid 19. Hasil penelitian bahwa penerapan perilaku hidup bersih dan sehat anak usia dini dalam kategori sangat baik, dari data Sebanyak 100\% atau 51 respondenanak cuci tangan dengan sabun sebelum 
makan. Sebanyak 98\% atau 50 responden anak jika keluar rumah menggunakan masker dan sebanyak $2 \%$ atau 1 responden anak jika keluar rumah tidak menggunakan masker. Sebanyak 100\% atau 51 responden anak jika sudah kembali kerumah langsung mandi dan mengganti baju dan sebanyak $100 \%$ atau 51 responden anak suka berjemur di pagi hari[11].

Rivanica menyatakan pertumbuhan berkaitan dengan perubahan dalam besar, jumlah, ukuran atau dimensi tingkat sel, organ maupun individu, yang bisa diukur dengan ukuran berat, ukuran panjang, umur tulang dan keseimbangan metabolic[12]. Stunting merupakan salah satu target tujuan pembangunan berkelanjutan ke-2 yaitu menghilangkan kelaparan dan segala bentuk malnutrisi pada tahun 2030 serta mencapai ketahanan pangan. Target yang ditetapkan adalah menurunkan angka stunting hingga 40\% pada tahun 2025. Prioritas pemerintah dalam menangani stunting diatur dalam Peraturan Menteri Kesehatan Nomor 39 Tahun 2016 tentang Pedoman Penyelenggaraan Program Indonesia Sehat dengan Pendekatan Keluarga, upaya yang dilakukan untuk menurunkan prevalensi stunting. Mengacu pada peraturan ini maka upaya menurunkan bahaya stunting pada balita antara lain (a) pemantauan pertumbuhan balita, (b) menyelenggarakan kegiatan Pemberian Makanan Tambahan (PMT) untuk balita, (c) menyelenggarakan stimulasi dini perkembangan anak dan (d) memberikan pelayanan kesehatan yang optimal. Optimalisasi keberhasilan upaya ini harus melibatkan semua pihak termasuk akademisi, tenaga kesehatan untuk edukasi ke guru PAUD dan orang tua[13].

Guru PAUD sebagai garda terdepan sebaiknya menyadari pentingnya penurunan prosentase stunting pada usia dini. Dikutip dari Tempo para guru PAUD harus memiliki pengetahuan dan keterampilan tentang stimulasi perkembangannya anak usia dini[14]. Terkait peranan orang tua dalam pencegahan stunting ini Madasari menegaskan pencegahan stunting yang paling efektif adalah pada periode 1000 Hari Pertama Kelahiran. Pemberian ASI dan gizi seimbang menjadi factor penentu dalam pertumbuhan anak. Orangtua, masyarakat, dan pemerintah harus berkomitmen untuk bersama-sama menyelesaikan permasalahan stunting. Ferdiaz menyebutkan untuk mencegah anak dari bahaya stunting dan bisa tumbuh tinggi ada 10 asupan nutrisi makanan yang bisa dikonsumsi antara lain vitamin A, vitamin B kompleks, vitamin D, vitamin $\mathrm{E}$, vitamin $\mathrm{K}$, mineral seng, kalsium dan magnesium[15].

Berdasarkan hasil wawancara dan observasi terhadap sebagian besar orangtua siswa di TK Labschool UPI KS, mereka belum mengetahui tentang stunting dan pengaruh gizi terhadap tumbuh kembang anak usia dini. Stunting atau pengerdilan seperti tinggi dan berat badan di bawah standar akan memengaruhi kondisi akademik anak di kelas. Oleh karena itu, orangtua perlu diberikan pemahaman terkait stunting disamping perlunya menyosialisasikan terkait bekal yang dibawa oleh anak yang sesuai, mengandung nutrisi yang seimbang dan diperlukan untuk masa pertumbuhannya sehingga dapat mencegah terjadinya stunting. 
PKM ini memfokuskan persoalan pada upaya edukatif tentang pengaruh stunting terhadap pertumbuhan dan perkembangan anak usia dini melalui kegiatan sosialisasi berupa diskusi, pengukuran tinggi dan berat badan serta praktik membuat menu bekal sehat bergizi yang disusun dalam bentuk buku menu sebagai luaran hasil PKM yang dilaksanakan. Adapun tujuan dilakukannya PKM ini adalah untuk:

1. Disosialisasikannya wawasan umum tentang stunting kepada guru dan orangtua siswa di TK Labschool UPI KS.

2. Diperoleh hasil pengukuran tinggi dan berat badan siswa TK Labschool UPI KS yang disesuaikan dengan standar WHO.

3. Dipraktekkannya penyusunan bahan bekal menu sehat bergizi seimbang oleh orangtua dan siswa secara kolaboratif

\section{METODE}

Metode pelaksanaan kegiatan pengabdian ini meliputi penyampaian materi pengabdian, praktik langsung (learning by doing) dan pendampingan. Adapun kegiatan pengabdian ini dilaksanakan dalam beberapa step yaitu sebagai berikut:

1. Preparing Step; Persiapan dilakukan selama 3 bulan dengan rincian kegiatan meliputi penyusunan materi kegiatan pengabdian, penyusunan tim pengabdi yang terdiri atas moderator, narasumber dan notulen kegiatan, penyusunan indikator evaluasi kegiatan, kunjungan awal dalam menyampaikan maksud dan tujuan dari kegiatan. Adapun rundown acara disusun sebagaimana yang terdapat pada tabel 1.

2. Do Step; Penyampaian materi pada step ini dilakukan selama dua hari dengan rincian kegiatan yang dilakukan meliputi penyampaian materi dan diskusi tentang stunting, pengukuran tinggi dan berat badan anak serta praktik menyusun menu bekal sehat bergizi yang bahannya disediakan oleh tim. Pada step ini, kegiatan dilakukan secara langsung yang melibatkan peran aktif peserta dan tim sebagai implementasi dari metode learning by doing yang dimaksud dalam tulisan ini. Adapun materi secara teoritis disampaikan dalam bentuk diskusi antara narasumber dan peserta (orangtua dan guru). Sementara siswa diarahkan untuk diukur tinggi dan berat badannya berdasarkan Indeks Massa Tubuh (IMT) anak usia 60-72 bulan atau setara dengan AUD usia 5-6 tahun (kelompok B). Sementara untuk anak usia 45 tahun (kelompok A) akan digunakan standar ukuran tinggi dan berat badan hasil modifikasi berbagai sumber.

3. Evaluation Step; Evaluasi pada step ini dilakukan selama dua minggu dengan rincian kegiatan meliputi evaluasi preparing step menggunakan pendekatan diskusi dan evaluasi do step yang melibatkan kembali orangtua dan anak dalam bentuk catatan testimony penggunaan buku saku menu bekal sehat bergizi yang dibagikan kepada partisipan. Selain itu, untuk hasil pengukuran tinggi dan berat badan anak dihitung menggunakan rumus berikut yang bersumber dari Rivanica dan Oxyandi[12]. 


\section{Berat Badan (BB) \\ Tinggi Badan x Tinggi Badan (TB2)}

Dengan interpretasi hasil proporsi standar yang digunakan yakni sebagai berikut:

1. Normal :-2 SD s.d. 2 SD atau gizi baik.

2. Kurus $:-3$ SD s.d. $<-2$ SD atau gizi kurang.

3. Kurus sekali : $<-3$ SD atau gizi buruk.

4. Gemuk $:>2$ SD s.d. 3 SD atau gizi lebih.

5. Gemuk sekali : $>3$ SD atau obesitas.

Berbeda dengan metode PKM, penulisan pada artikel ini menggunakan metode deskriptif-naratif. Khususnya, tulisan ini ingin menggambarkan secara naratif tentang pelaksanaan kegiatan Pengabdian kepada Masyarakat (PKM) yang dilakukan terhadap peserta sosialisasi materi tentang stunting dan tumbuh kembang anak sebagai objek kajian PKM. Sidiq dalam blognya menyatakan bahwa metode penelitian deskriptif merupakan yang proses pengumpulan datanya memungkinkan peneliti untuk menghasilkan deskripsi tentang fenomena sosial yang diteliti. Melalui data deskriptif, peneliti mampu mengidentifikasi mengapa, apa dan bagaimana fenomena sosial terjadi[16]. Dalam konteks penulisan artikel dari hasil PKM ini kami memutuskan untuk menggunakan modifikasi pendekatan deskriptif-naratif agar dapat menggambarkan secara rinnci mengenai proses pelaksanaan PKM dalam bentuk sosialisasi, karena narasi merupakan salah satu pendekatan penulisan deskriptif yang mana menurut Webster dan Metrova (dalam Mawardi), narasi (narrative) adalah suatu metode penelitian di dalam ilmu-ilmu sosial. Inti dari metode ini adalah kemampuannya untuk memahami identitas dan pandangan dunia seseorang dengan mengacu pada cerita-cerita (narasi) yang ia dengarkan ataupun tuturkan di dalam aktivitasnya sehari-hari[17].

\section{Tabel 1.}

\section{Rundown Kegiatan PKM Stunting TK Labschool}

\begin{tabular}{|c|c|c|}
\hline Waktu & Kegiatan & Petugas \\
\hline $07.45-08.00$ & $\begin{array}{l}\text { Registrasi ulang (absensi, } \\
\text { pembagian seminar kit, celemek } \\
\text { orangtua dan anak, face shield }\end{array}$ & Loveita Setyarini, S.Pd \\
\hline $08.00-08.10$ & Pembukaan. & $\begin{array}{l}\text { Rr. Deni Widjayatri, M.Pd. } \\
\text { Vina Ni.matun, S.Pd (MC dan } \\
\text { moderator) }\end{array}$ \\
\hline $08.10-09.00$ & $\begin{array}{l}\text { Stunting dan Kaitannya dengan } \\
\text { Tumbuh Kembang Anak Usia Dini } \\
\text { (Bekal Sehat Bergizi untuk Anak). } \\
\text { Diskusi (tanya jawab). }\end{array}$ & $\begin{array}{l}\text { Dr. Yulianti Fitriani., S.Pd., M. } \\
\text { Sn (narasumber) } \\
\text { Vina Ni.matun, S.Pd (MC dan } \\
\text { moderator) }\end{array}$ \\
\hline 09.00- 09.30 & $\begin{array}{l}\text { Pengukuran tinggi badan dan } \\
\text { berat badan anak TK Labschool } \\
\text { Kampus UPI di Serang }\end{array}$ & $\begin{array}{l}\text { Budhi Tristyanto, M.Pd } \\
\text { Loveita Setyarini, S.Pd }\end{array}$ \\
\hline $09.10-09.30$ & $\begin{array}{l}\text { Simulasi Membuat Bekal Sehat } \\
\text { Bergizi (Membuat Burger) }\end{array}$ & $\begin{array}{l}\text { Loveita Setyarini, S.Pd } \\
\text { Rr. Deni Widjayatri, M.Pd }\end{array}$ \\
\hline
\end{tabular}




\section{HASIL DAN PEMBAHASAN}

Pemaparan materi melalui tayangan berupa slide power point menjadi media bantu yang digunakan dalam kegiatan sosialisasi. Berikut ulasan singkat mengenai materi yang disampaikan pada saat sosialisasi.

Stunting menyebabkan perkembangan otak dan fisik terhambat membuat anak rentan terhadap penyakit, sulit berprestasi dan saat dewasa mudah menderita obesitas sehingga berisiko terkena penyakit jantung, diabetes dan penyakit tidak menular lainnya. Menurut Dewi seorang anak dikatakan stunting jika ukuran badannya lebih pendek dari anak seusianya, proporsi tubuh cenderung normal namun terlihat lebih muda/kecil, berat badan rendah dan pertumbuhan tulang tertunda. Penyebab terjadinya stunting sebagaimana yang terlihat pada gambar 1 , bahwa terdapat 5 penyebab yang dapat memengaruhi terhambatnya tumbuh kembang anak dalam masa emas yang menjadi masa keuntungan bagi AUD. Seperti adanya perubahan hormon yang dipicu oleh kondisi stress pada anak saat pemberian tugas sekolah di masa pandemi. Hal ini menjadi salah satu kondisi yang selayaknya dipertimbangkan agar tidak terjadi perubahan-perubahan hormonal yang secara tidak disadari melingkupi ruang aktivitas belajar anak sehingga dapat memicu terjadinya stunting[18].

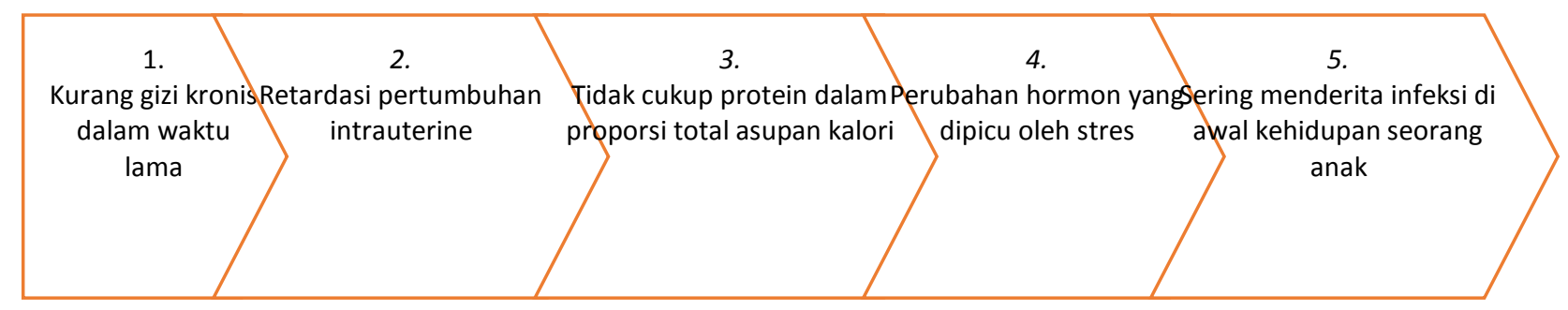

\section{Gambar 1.}

\section{Penyebab Terjadinya Stunting}

Di Indonesia, wilayah dengan angka stunting tertinggi berada di Kabupaten Ogan Komering Ilir (OKI) dengan prosentase dampak buruk yang diakibatkannya berada pada status dimana banyak terdapat anak dengan ukuran tinggi dan berat badan di bawah normal, hambatan-hambatan dalam hal kemampuan akademik serta kurangnya rasa percaya diri. Dalam hal ini, baik pemerintah daerah, masyarakat maupun para stake holder terkait akan terus berupaya melakukan upaya-upaya untuk menanggulangi dan menurunkan angka stunting di berbagai daerah. Sehingga dalam materi sosialisasi ini, upaya preventif yang ditawarkan adalah sebagai berikut:

1. Suplementasi makanan, praktik pemberian makan yang optimal dan pemberian ASI eksklusif.

2. Program terkait kesadaran anak, yang menargetkan populasi pedesaan yang tidak terjangkau untuk mengurangi stunting pada masa kanak-kanak di tingkat populasi. 
3. Kolaborasi sebagai wujud upaya bersama yang melibatkan pemerintah, organisasi nonpemerintah dan akademisi sebagai upaya untuk meningkatkan status gizi pada anak.

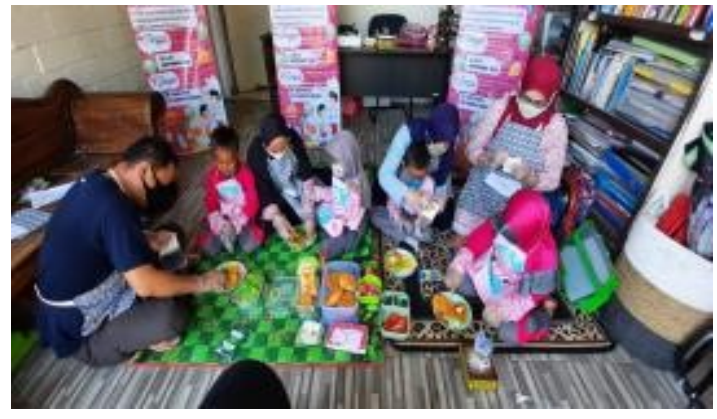

Gambar 2.

\section{Kolaborasi orangtua dan siswa saat menyusun menu bekal sehat bergizi}

(dok. Foto: Rr. Deni W.)

Berdasarkan hasil pengukuran tinggi dan berat badan terhadap siswa TK Labschool UPI KS diperoleh kesimpulan bahwa sebagian besar siswa berada pada kategori proporsi normal atau gizi baik hingga gemuk atau gizi lebih. Informasi pada Tabel 2 merupakan hasil pengukuran yang diolah dengan menggunakan rumus pada IMT pada kelompok B (usia 5-6 tahun). Meskipun demikian, pada kesempatan PKM kali ini pengukuran juga dilakukan terhadap siswa kelompok A dengan merujuk pada tinggi dan berat badan ideal rata-rata anak usia 4-5 tahun menurut Kementerian Kesehatan $\mathrm{RI}[19]$.

Disebutkan bahwa tinggi badan ideal anak berusia empat tahun adalah 94,1 111,3 sentimeter (perempuan) dan 94,9 - 111,7 sentimeter (laki-laki). Sedangkan berat badan idealnya adalah 12,3 - 21,5 kilogram (perempuan) dan 12,7 - 21,2 kilogram (lakilaki). Sementara itu untuk tinggi badan ideal anak berusia lima tahun adalah 99,9 118,9 sentimeter (perempuan) dan 100,7 - 119,3 sentimeter (laki-laki). Sedangkan untuk berat badan idealnya adalah 13,7 - 24,9 kilogram (perempuan dan 14,1 - 24,2 kilogram (laki-laki).

Tabel 2.

Daftar Ukuran Tinggi dan Berat Badan Siswa TK Labschool UPI Kampus Serang

\begin{tabular}{|c|c|c|c|c|c|c|c|}
\hline \multirow{2}{*}{$\begin{array}{c}\text { No } \\
\text {. }\end{array}$} & \multirow{2}{*}{ Nama Siswa } & \multicolumn{2}{|c|}{ Kelompok A } & \multirow{2}{*}{ No. } & \multirow{2}{*}{ Nama Siswa } & \multicolumn{2}{|c|}{ Kelompok B } \\
\hline & & TB & $\mathrm{BB}$ & & & TB & $\mathrm{BB}$ \\
\hline 1. & Azam (4 Thn) & $108 \mathrm{~cm}$ & $17,9 \mathrm{~kg}$ & 1. & Azran (5 Thn) & $113 \mathrm{~cm}$ & $18,2 \mathrm{~kg}$ \\
\hline 2. & Alea (5 Thn) & $113 \mathrm{~cm}$ & $18,5 \mathrm{~kg}$ & 2. & Rio (5 Thn) & $111 \mathrm{~cm}$ & $18,8 \mathrm{~kg}$ \\
\hline 3. & Azkya (4 Thn) & $107 \mathrm{~cm}$ & $23,4 \mathrm{~kg}$ & 3. & Acha (5 Thn) & $118 \mathrm{~cm}$ & $30 \mathrm{~kg}$ \\
\hline 4. & Alya (4 (Thn) & $107 \mathrm{~cm}$ & $15,8 \mathrm{~kg}$ & 4. & Kia (5 Thn) & $109 \mathrm{~cm}$ & $18,3 \mathrm{~kg}$ \\
\hline 5. & Aleeta (4 (Thn) & $100 \mathrm{~cm}$ & $13,3 \mathrm{~kg}$ & & & & \\
\hline
\end{tabular}

Terdapat dua siswa dengan tinggi dan berat badan melebihi batas ideal yang berdampak pada aktivitas keseharian di rumah maupun di sekolah. Hal ini perlu 
dilakukan perbaikan pola makan dan kegiatan olah tubuh, terutama yang dapat membantu menurunkan berat badan seperti mengatur menu bekal sehat dengan gizi yang seimbang, tidak berlebih. Kegiatan mengukur tinggi dan berat badan dapat dilihat pada gambar 3 .

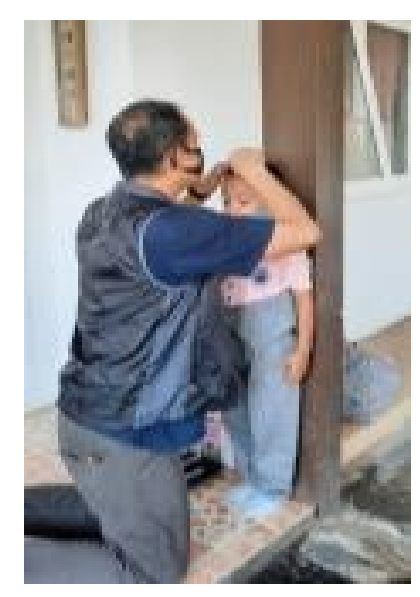

\section{Gambar 3.}

Pengukuran tinggi dan berat badan oleh tim PKM (dok. Foto: Rr. Deni W.)

Sebagai output kegiatan, tim menyusun referensi menu makanan yang cocok dan baik untuk dibagikan kepada peserta sosialisasi dalam bentuk buku saku. Buku ini berisi beberapa menu pilihan makanan dari berbagai sumber dengan harapan dapat dipergunakan pada saat orangtua menyiapkan bekal sekolah untuk anak-anaknya. Secara singkat, contoh layout buku saku tersebut terlihat pada gambar 4 .
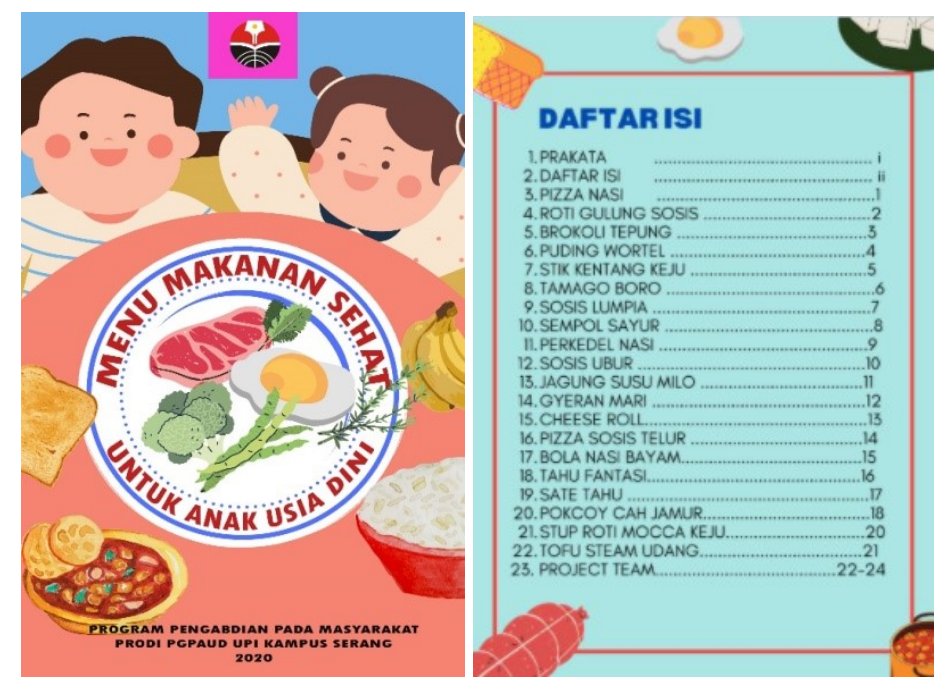

Gambar 4

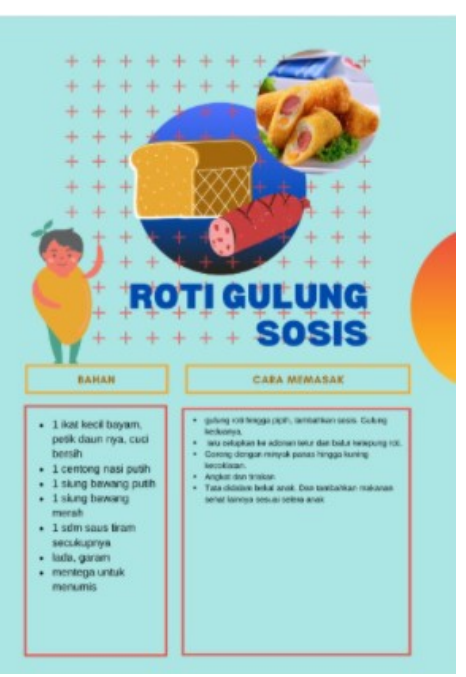

Layout buku menu sehat bergizi sebagai output PKM

PKM dilaksanakan selama dua hari yaitu Selasa 10 september 2020 dan Rabu, 11 September 2020, pukul 08.00 - 10.00 WIB. Dengan rangkaian aktivitas pengondisian (pemasangan banner dan infokus), daftar ulang (cuci tangan/hand sanitizer, pengukuran 
suhu tubuh, mengisi presensi kehadiran, penyerahan seminar kit dan snack untuk orangtua dan anak, pembukaan oleh ketua PKM, sosialisasi pengaruh stunting pertumbuhan dan perkembangan AUD oleh narasumber, pengukuran tinggi dan berat badan oleh tim PKM, serta pembuatan burger sehat bergizi yang dipandu oleh kepala sekolah dan guru TK Labschool UPI KS. Berdasarkan testimony orangtua siswa yang terekam dan telah publish di media beberapa media online mengharapkan agar kegiatan ini dapat dilakukan kembali sehingga bisa menambah wawasan terkait parenting tumbuh kembang anak.
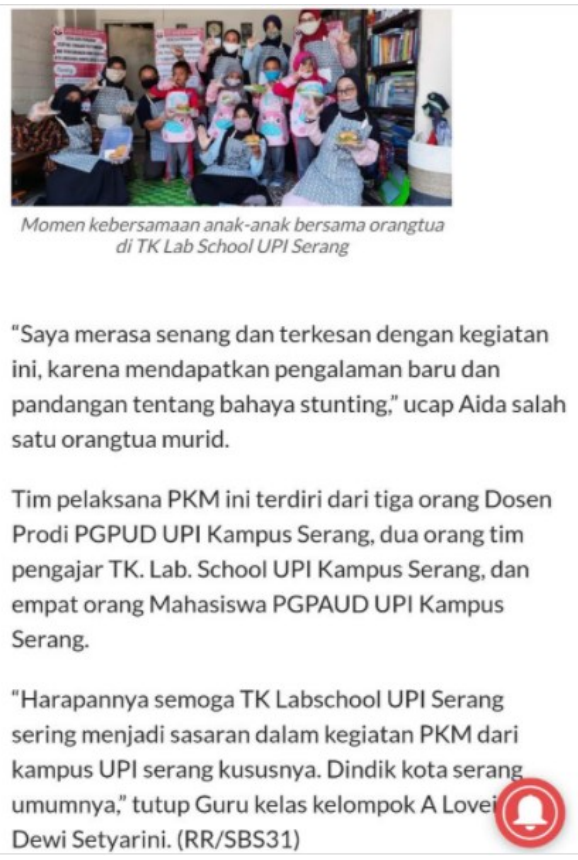

\section{Gambar 5.}

Testimony Guru dan orangtua

Situasi pandemi Covid-19 menjadi pertimbangan perubahan lokasi pelaksanaan kegiatan dengan dilaksanakan di rumah orangtua siswa sehingga jumlah peserta lebih sedikit. Bagi peserta yang tidak hadir, seminar kit tetap dibagikan dengan cara dititipkan ke guru TK. Dengan demikian proses edukasi bisa merata. Adapun buku saku menu bekal sehat murah bergizi diberikan setelah selesai proses pencetakan yaitu bulan Oktober. Tim akan memberikan link google form yang harus diisi oleh orangtua terkait saran tentang kegiatan sosialisasi dan menu apa saja yang sudah dipraktekkan. Apabila sebelumnya di TK hanya ada alat ukur tinggi badan, kini sudah ada pengukur berat badan. Tim menyarankan untuk mengukur tinggi dan berat badan siswa minimal 1 bulan sekali.

\section{KESIMPULAN}

Stunting yang merupakan kondisi pengerdilan pada tubuh anak sangat berpengaruh pada kesehatan dan gizi anak. Pentingnya pemahaman mengenai pengaruh 
stunting terhadap pertumbuhan dan perkembangan anak usia dini akan berdampak pada penanggulangan gizi buruk pada anak. Pentingnya pengetahuan mengenai konsep tumbuh kembang anak dan stunting merupakan hal sederhana dan terdekat yang dapat dijadikan gagasan dalam sebuah kegiatan PKM. Sebagai isu yang menarik, dirasa penting agar masyarakat dapat mengenal, memahami dan mampu mengantisipasi hingga mencegah terjadinya stunting. Oleh karena itu, hasil dari kegiatan PKM ini akan ditawarkan kepada penyelenggara pendidikan anak usia dini agar dapat menjadikan kegiatan ini sebagai program yang dilakukan secara rutin sebagai upaya pencegahan stunting khususnya bagi peserta didik di TK Labschool UPI KS maupun anak-anak AUD pada umumnya.

\section{PENGHARGAAN}

Kegiatan PKM ini dapat terselenggara dengan baik karena didukung dan dibiayai dari RKAT Program Studi PGPAUD UPI KS, untuk itu disampaikan terima kasih yang setinggi-tingginya atas kesempatan pengabdian ini. Apresiasi dan ucapan terima kasih disampaikan pula kepada tim PKM yang membantu dengan penuh tanggungjawab dan berdedikasi. Tak lupa kepada seluruh partisipan; guru, orangtua dan peserta didik dari TK Labschool UPI KS yang dengan penuh semangat mengikuti seluruh rangkaian kegiatan dengan baik.

\section{REFERENSI}

[1] I. Picauly and S. M. Toy, "Analisis determinan dan pengaruh stunting terhadap prestasi belajar anak sekolah di Kupang dan Sumba Timur, NTT," J. Gizi dan Pangan, vol. 8, no. 1, pp. 55-62, 2013.

[2] R. I. Kemenkes, "Data dan informasi profil kesehatan indonesia," Jakarta Kemenkes RI, 2017.

[3] R. Akram, M. Sultana, N. Ali, N. Sheikh, and A. R. Sarker, "Prevalence and determinants of stunting among preschool children and its urban--rural disparities in Bangladesh," Food Nutr. Bull., vol. 39, no. 4, pp. 521-535, 2018.

[4] A. Amirullah, A. Try, A. Putra, A. Daud, and A. Kahar, "Deskripsi Status Gizi Anak Usia 3 Sampai 5 Tahun Pada Masa Covid 19,” vol. 1, no. 2, pp. 16-27, 2020.

[5] S. Udu, L. O. Anhusadar, A. Alias, and L. Ali, "Hedole Dole : Stunting Tradisional Masyarakat Wakatobi," Al-Izzah J. Hasil-Hasil Penelit., vol. 14, no. 2, p. 32, Dec. 2019.

[6] H. Kismul, P. Acharya, M. A. Mapatano, and A. Hatløy, "Determinants of childhood stunting in the Democratic Republic of Congo: further analysis of Demographic and Health Survey 2013--14," BMC Public Health, vol. 18, no. 1, p. 74, 2018.

[7] B. T. Crookston et al., "Children who recover from early stunting and children who are not stunted demonstrate similar levels of cognition," J. Nutr., vol. 140, no. 11, pp. 1996-2001, 2010.

[8] L. Handayani, S. A. Mulasari, N. Nurdianis, F. K. Masyarakat, and U. A. Dahlan, "Evaluasi Program Pemberian Makanan Tambahan Anak Balita Evaluation of Supplement Feeding ' S Programme To Children Under Five Years Old," J. Manaj. Pelayanan Kesehat., vol. 11, no. 01, pp. 21-26, 2008.

[9] Zulfa Husni Khumayra; Madya Sulisno, "Perbedaan Pengetahuan Dan Sikap Perilaku Hidup Bersih,” J. Nurs. Stud., vol. 1, no. 1, pp. 197-204, 2012. 
[10] H. I. Safitri and H. Harun, "Membiasakan Pola Hidup Sehat dan Bersih pada Anak Usia Dini Selama Pandemi Covid-19," J. Obs. J. Pendidik. Anak Usia Dini, vol. 5, no. 1, p. 385, Jun. 2020.

[11] L. Anhusadar and I. Islamiyah, "Penerapan Perilaku Hidup Bersih dan Sehat Anak Usia Dini di Tengah Pandemi Covid 19," J. Obs. J. Pendidik. Anak Usia Dini, vol. 5, no. 1, p. 463, Jul. 2020.

[12] R. Rivanica and M. Oxyandi, "Buku ajar deteksi dini tumbuh kembang dan pemeriksaan bayi baru lahir," Jakarta Salemba Med., 2016.

[13] R. I. Kemenkes, "Peraturan Menteri Kesehatan Nomor 39 Tahun 2016," Tentang Pedoman Penyelenggaraan Progr. Indones. Sehat Dengan Pendekatan Keluarga, Jakarta, 2016.

[14] Tempo, "Guru PAUD Garda Terdepan Pencegahan Stunting," Tempo.co., 2018. [Online]. Available: nasional.tempo.co/read/1146157/guru-paud-gardaterdepan-pencegahan-stunting.

[15] Nikita Yulia Ferdiaz, "Berantas Stunting: Takut Anak Tumbuh Pendek? Coba Berikan 9 Makanan Penambah Tinggi Badan," https://health.grid.id, 2020. [Online]. Available: https://health.grid.id/read/351995417/berantas-stuntingtakut-anak-tumbuh-pendek-coba-berikan-9-makanan-penambah-tinggibadan?page=all.

[16] H. Siddiq, "Metode Penelitian Deskriptif," Blogs, 2018. [Online]. Available: http://sosiologis.com/metode-penelitian-deskriptif.

[17] Rizal Mawardi, "Penelitian Kualitatif Pendekatan Naratif," perbanas.id, 2018. [Online]. Available: https://dosen.perbanas.id/penelitian-kualitatif-pendekatannaratif/.

[18] Dewi Bestari Kumala, "Mengenal Stunting dan Efeknya pada Pertumbuhan Anak," lifestyle.kompas.com, $2017 . \quad$ [Online]. Available: https://lifestyle.kompas.com/read/2017/02/08/100300123/mengenal.stunting. dan.efeknya.pada.pertumbuhan.anak?page=all.

[19] Halodoc, "Tahap Pertumbuhan Anak Sesuai Usia 4-5 Tahun," www. Halodoc.com, 2018. [Online]. Available: https://www.halodoc.com/artikel/tahap-pertumbuhananak-sesuai-usia-4-5-tahun. 